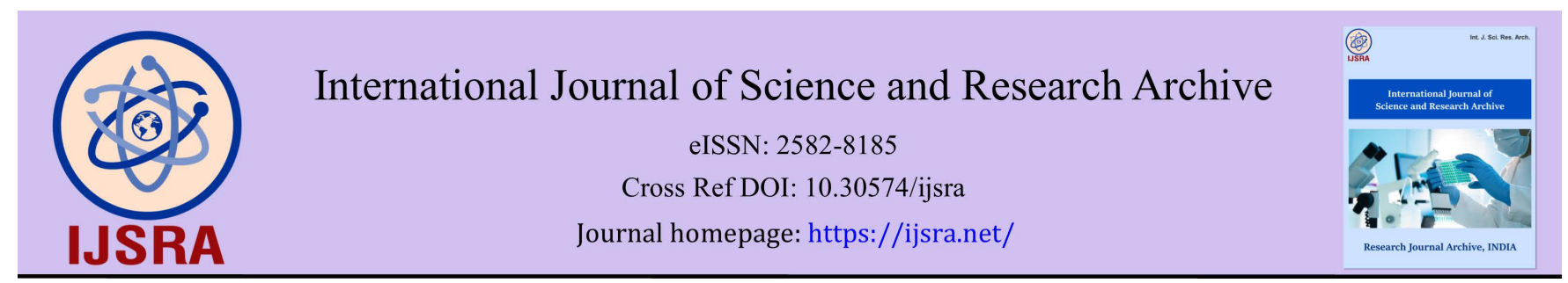

(RESEARCH ARTICLE)

Check for updates

\title{
A survey of COVID-19 linked experience, knowledge, attitude, and behaviours among orthodontists and orthodontic residents in Nigeria
}

Tolulase Abosede Yemitan 1,2, , Omolara Yeside Odunsi 2, Oyeyemi Oyebola Oyewo ${ }^{2}$, Kikelomo Oluwabukola Adegbite ${ }^{2}$, Aderinsola Sophia Omotuyole ${ }^{1,2}$ and Babatunde Ogunbiyi Ogunbanjo ${ }^{1,2}$

${ }^{1}$ Department of Child Dental Health, Lagos State University College of Medicine, Ikeja, Lagos, Nigeria.

2 Department of Child Dental Health, Lagos State University Teaching Hospital, Ikeja, Lagos, Nigeria.

International Journal of Science and Research Archive, 2021, 03(02), 006-018

Publication history: Received on 10 July 2021; revised on 19 August 2021; accepted on 21 August 2021

Article DOI: https://doi.org/10.30574/ijsra.2021.3.2.0119

\begin{abstract}
Background: Orthodontic practitioners have a high exposure risk to cross infection with COVID-19 due to proximity with the patients and frequent exposure to body fluids during procedures.
\end{abstract}

Objectives: This study aimed to investigate COVID-19 related experiences, knowledge, attitudes, and behaviours among orthodontists and orthodontic residents in Nigeria, and to identify factors related with their self-perceived and actual level of COVID-19 related knowledge.

Methods: An online questionnaire was sent to a sample of orthodontists and orthodontic residents in Nigeria to survey demographic characteristics, personal experiences, knowledge, attitude and behaviours related to the COVID-19 pandemic. The data collected were analysed using descriptive analysis, chi-square test and regression analysis.

Results: A total of 29 (54.7\%) respondents were specialist orthodontists while 24(45.3\%) were orthodontic residents. Most orthodontists (96.6\%) and orthodontic residents (95.8\%) had completed COVID-19-related training programs and the Internet (98.1\%) was their primary source of knowledge. The mean self-perceived knowledge score was $4.44 \pm$ 0.55 while their total knowledge score was $4.15 \pm 0.60$. Attitudes towards the use of PPE $(P=0.001)$ and compliance with the use of pre-procedural mouth rinse with $1 \%$ Hydrogen Peroxide or $0.2 \%$ povidone Iodine $(P=0.034)$ was significantly different among the respondents based on their professional status.

Conclusions: COVID-19-related training programs as well as provision of essential personal protective equipment are essential for the improvement of knowledge, confidence, and preparedness of orthodontic professionals.

Keywords: COVID-19; Coronavirus; Infection control; Orthodontics; Knowledge; Attitude

\section{Introduction}

Individuals in close contact with symptomatic or asymptomatic coronavirus disease-2019 (COVID-19) patients such as healthcare workers are at higher risk of cross-infection [1]. In particular, high-speed rotary handpieces and ultrasonic instruments produce contaminated aerosols and droplets which may predispose dental practitioners to infection.

Control of COVID-19 in the orthodontic centres is challenging [1] prompting several health regulating agencies and Associations to make several recommendations, including 14-days quarantine for an individual that has been in high

\footnotetext{
${ }^{*}$ Corresponding author: Tolulase Abosede Yemitan

Department of Child Dental Health, Lagos State University College of Medicine, Ikeja, Lagos, Nigeria.

Copyright $(2021$ Author(s) retain the copyright of this article. This article is published under the terms of the Creative Commons Attribution Liscense 4.0.
} 
risk regions 14 days prior, suspension of non-emergency orthodontic care in the regions where COVID-19 has spread [1,2], a questionnaire screening of patients to take different actions according to the triage of the patients [3], temperature screening of each patient using contact-free forehead thermometers [4], pre-procedural mouthrinses to reduce droplets and aerosols generated during procedures [5], hand hygiene, use of personal protective equipment (PPE), including safety goggles, masks, gloves, face shields, and protective gowns [6]. As the world struggles with the COVID-19 pandemic, orthodontists have had to change their routine clinical attitudes and practices.

Orthodontic care is provided in both public and private dental facilities in Nigeria [7], mostly located in urban areas with close to fifty residents in training [8]. Few studies in Nigeria have investigated COVID-19 related impacts and perceptions among general population and dental practitioners [7,9]. However, none has investigated the knowledge, behaviours and attitudes regarding COVID-19 outbreak among Nigerian orthodontic practitioners.

Therefore, the objectives of this study were (1) to assess the current COVID-19-related experiences, knowledge, attitudes, and behaviors among orthodontists and orthodontic residents in Nigeria; (2) to identify factors associated with the self-perceived and actual level of knowledge in the study participants.

\section{Material and methods}

\subsection{Ethics}

The cross-sectional study was conducted using a purposive sampling technique with a study population made up of all orthodontists and orthodontic residents in Nigeria. A 39-item online questionnaire was developed based on previous research [10] in Google Forms that received approval from the appropriate Research Ethics Committee. All participants voluntarily participated in this study and were informed about the nature of the study.

\subsection{Survey Design}

The survey consisted of four aspects: background information, knowledge, attitudes, and behaviours. The first 13 questions were regarding the background characteristics, including five for demographics, four for workplace information, and four for COVID-related personal experience. Ten questions were in the knowledge section, including three Likert-scale items (\#14, \#16, and \#17) for the self-perceived level of knowledge, one question (\#15) for their source of knowledge, and six ( 3 single-choice and 3 multiple-choice, \#18 to \#23) questions for the assessment of actual knowledge level. Among five questions in the attitude section, four were Likert-scale (\#24 to \#27) to evaluate the attitudes toward PPE in the context of COVID-19. In addition, a yes/no question (\#28) about willingness to treat/care for orthodontic patients with confirmed or suspected COVID-19, and if "no" was selected, a reason should be chosen for their choice (\#29). The behaviour section contained ten questions to rate their behaviours after the resumption of orthodontic services using ten Likert-scale questions (\#30 to \#39). For all Likert-scale questions, a five-point Likert scale was used ranging from 1 (completely disagree) to 5 (completely agree).

\subsection{Participant Recruitment}

Prior to its official release, the questionnaire was sent to a small group of 8 orthodontic practitioners to check if the questions were clear and unambiguous. After this pilot survey, the questionnaire was distributed and publicized to orthodontists and orthodontic residents nationwide.

The prepared e-survey forms were sent to specialist orthodontists and orthodontic residents in Nigeria who were members of the Nigerian Association of Orthodontists (NAO), with three follow-up reminders sent at 7-day intervals via postings on WhatsApp that included a link to the survey available from August $25^{\text {th }}$ and September $6^{\text {th }}, 2020$. Those working outside Nigeria, retired orthodontists and non-specialists were excluded. Questionnaires with incomplete responses were excluded.

There were approximately 97 orthodontists and orthodontic residents practicing in Nigeria who met the criteria. The first mailing resulted in 45 returned questionnaires. Follow up mailing to non-responders yielded an additional 8 questionnaires. A 54.6\% response rate was attained. 


\subsection{Statistical Analysis}

Data analysis was done with the Statistical Package for Social Sciences (SPSS) version 22 (IBM Corp, Armonk, NY). The self-perceived level of knowledge about COVID-19 was evaluated as a mean of the scores of three Likert-scale items (\#14, \#16, and \#17). To evaluate the actual level of knowledge, 1 point was given for each question of \#18 to \#23 answered correctly, with no point for any item incorrectly answered. Then, a total knowledge score (score range: 0 to 6) was calculated by adding the scores of all these six items for each respondent.

Descriptive statistics were performed to review the characteristics of each question. Categorical data were analysed with chi-square tests with data presented as counts and percentages, continuous data were expressed as means and standard deviations (SDs) and Likert-scale answers were presented as medians and interquartile ranges. The selfperceived level of knowledge and the total knowledge score were compared using one-way analysis of variance (ANOVA) with Tukey modification. Linear regression analyses were performed to explore factors associated with the self-perceived level of knowledge and total knowledge score. The significance level was set at $P<0.05$.

\section{Results}

\subsection{General Information}

The respondents were from 7 of the 36 States and a Federal Capital Territory of Nigeria. Figure 1 illustrates the geographical distribution of respondents with the cumulative number of confirmed COVID-19 cases in each region as of September 6, 2020. There were 14 (26.4\%) males and 39 (73.6\%) females. Most of the respondents were orthodontists (54.7\%), followed by Senior orthodontic residents (30.2\%) and Junior orthodontic residents (15.1\%). Few (28.3\%) of them had a relatively short working experience in orthodontics ( $\leq 5$ years). Table 1 shows the socio-demographic characteristics of study participants.

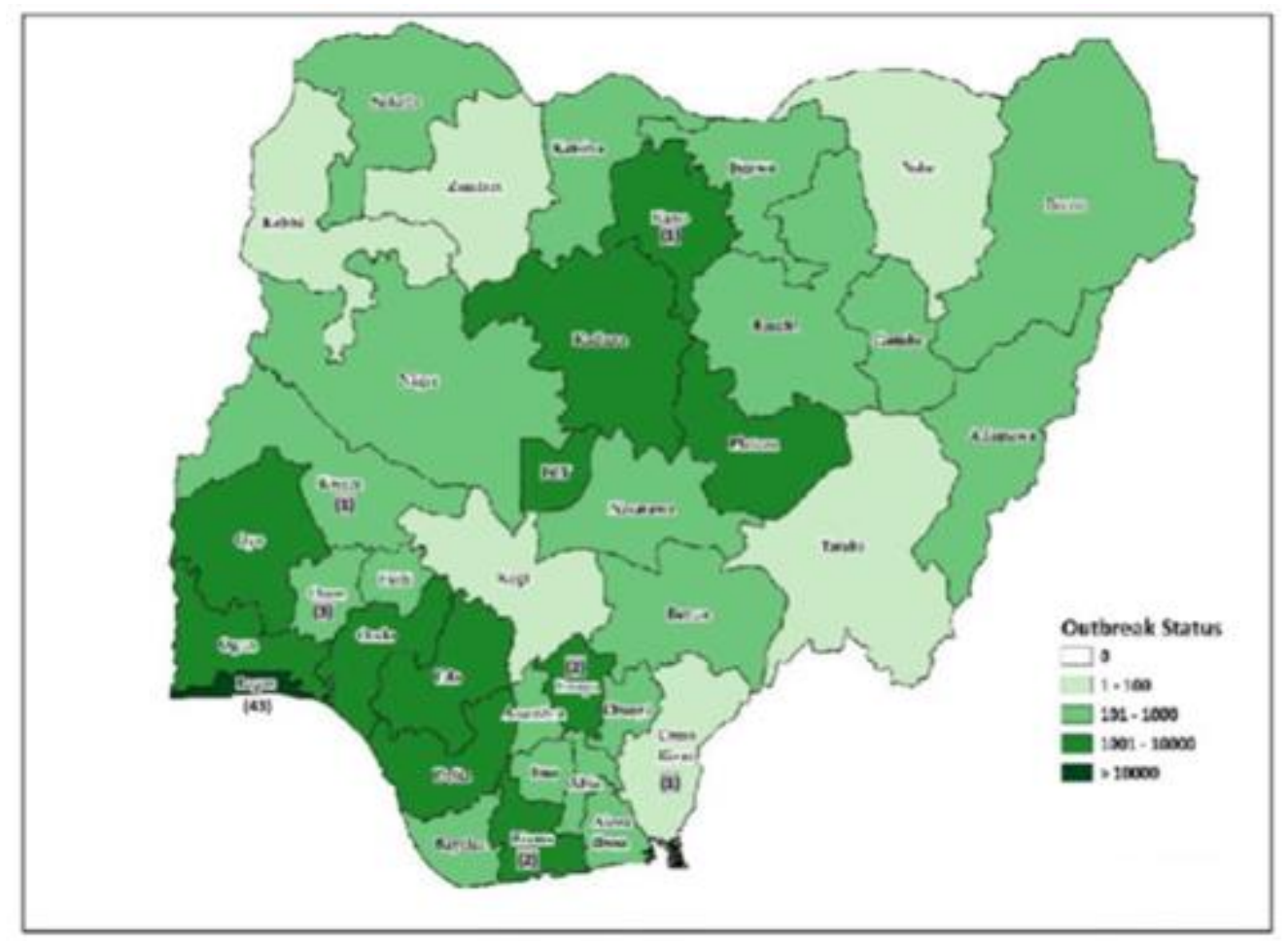

Figure 1 Geographical distribution of respondents to this survey $(n=53)$. Gradient of colours represents the cumulative number of confirmed COVID-19 cases in each State (as of September 6, 2020) of Nigeria. Numbers in parentheses indicate the number of respondents from each State 
Table 1 Socio-demographic characteristics of participants

\begin{tabular}{|c|c|c|}
\hline Characteristics & $\mathbf{N}$ & Percentage \\
\hline \multicolumn{3}{|l|}{ Demographics } \\
\hline \multicolumn{3}{|l|}{ Age group (Years) } \\
\hline $21-30$ & 5 & 9.4 \\
\hline $31-40$ & 15 & 28.3 \\
\hline $41-50$ & 23 & 43.4 \\
\hline $51-60$ & 7 & 13.2 \\
\hline$>60$ & 3 & 5.7 \\
\hline \multicolumn{3}{|l|}{ Gender } \\
\hline Male & 14 & 26.4 \\
\hline Female & 39 & 73.6 \\
\hline \multicolumn{3}{|l|}{ Marital status } \\
\hline Single & 7 & 13.2 \\
\hline Married & 44 & 73.0 \\
\hline Others & 2 & 3.8 \\
\hline \multicolumn{3}{|l|}{ Cadre } \\
\hline Junior resident & 8 & 15.1 \\
\hline Senior resident & 16 & 30.2 \\
\hline Specialist/ consultant orthodontics & 29 & 54.7 \\
\hline \multicolumn{3}{|l|}{ Years of orthodontics practice } \\
\hline$\leq 5$ & 15 & 28.3 \\
\hline $6-10$ & 14 & 26.4 \\
\hline $11-15$ & 13 & 24.5 \\
\hline $16-20$ & 5 & 9.4 \\
\hline$>20$ & 6 & 11.3 \\
\hline \multicolumn{3}{|l|}{ Workplace Information } \\
\hline \multicolumn{3}{|l|}{ Location of practice } \\
\hline Lagos & 43 & 81.1 \\
\hline Other States & 10 & 18.9 \\
\hline \multicolumn{3}{|l|}{ Workplace } \\
\hline Hospital & 41 & 77.4 \\
\hline Clinic & 12 & 22.6 \\
\hline \multicolumn{3}{|l|}{ Work setting } \\
\hline Private & 11 & 20.8 \\
\hline Government & 33 & 62.3 \\
\hline Armed forces & 4 & 7.5 \\
\hline Private/ Government & 5 & 9.4 \\
\hline \multicolumn{3}{|c|}{ Number of orthodontists in practice in Centre } \\
\hline Solo & 9 & 17.0 \\
\hline $2-9$ & 40 & 75.5 \\
\hline$\geq 10$ & 4 & 7.5 \\
\hline Total & 53 & 100.0 \\
\hline
\end{tabular}




\subsection{Personal Experience}

Table 2 shows the respondents' COVID-19-related personal experience during the epidemic. Although 32.1\% of them had participated in anti-epidemic activities, such as supporting fever clinics or designated COVID-19 hospitals, and acting as community volunteers, only $11.3 \%$ had the experience of treating or caring for patients with confirmed COVID19. Additionally, most orthodontists and orthodontic residents (96.2\%) had finished COVID-19-related training programs.

Table 3 showed that the proportion of respondents that had not resumed orthodontic work was not significantly different based on geographical location. In addition, the experience of treating or caring for COVID-19 patients was solely among respondents from Lagos (14.0\%) compared to those from areas outside Lagos.

Table 2 Respondents' personal experience during the COVID-19 epidemic by professional status

\begin{tabular}{|c|c|c|c|c|c|}
\hline Personal experience $^{\dagger}$ & $\begin{array}{l}\text { Orthodontists } \\
\qquad \mathrm{N}=29\end{array}$ & $\begin{array}{c}\text { Senior } \\
\text { residents } \\
\mathrm{N}=16\end{array}$ & $\begin{array}{c}\text { Junior } \\
\text { residents } \\
\mathrm{N}=8\end{array}$ & $\begin{array}{c}\text { Total } \\
N=53\end{array}$ & $\begin{array}{c}\text { P- } \\
\text { value }\end{array}$ \\
\hline \multicolumn{6}{|c|}{ Participation in anti-epidemic activities } \\
\hline Yes & $10(34.5)$ & $5(31.3)$ & $2(25.0)$ & $17(32.1)$ & 0.875 \\
\hline None & $19(65.5)$ & 11(68.7) & $6(75.0)$ & $36(67.9)$ & \\
\hline \multicolumn{6}{|l|}{ Status of orthodontic services } \\
\hline Not resumed yet & $0(0)$ & $0(0)$ & $2(25)$ & $2(3.8)$ & \\
\hline Resumed, $2-4$ weeks & $0(0)$ & $1(6.3)$ & $0(0)$ & $1(1.9)$ & $0.023^{*}$ \\
\hline Resumed, more than 4 weeks & $28(96.6)$ & $15(93.8)$ & $6(75.0)$ & $49(92.5)$ & \\
\hline No suspension & $1(3.4)$ & $0(0)$ & $0(0)$ & $1(1.9)$ & \\
\hline \multicolumn{6}{|c|}{ Completion of COVID-19 related training program } \\
\hline Yes & $28(96.6)$ & $16(100)$ & $7(87.5)$ & $51(96.2)$ & 0.314 \\
\hline No & $1(3.4)$ & $0(0)$ & $1(12.5)$ & $2(3.8)$ & \\
\hline \multicolumn{6}{|c|}{ Experience of treating and caring for COVID-19 patients } \\
\hline Yes & $4(13.8)$ & $1(6.3)$ & $1(12.5)$ & $6(11.3)$ & 0.742 \\
\hline No & $25(86.2)$ & $15(93.8)$ & $7(87.5)$ & $47(88.7)$ & \\
\hline
\end{tabular}

Table 3 Respondents' personal experience during the COVID-19 epidemic by location

\begin{tabular}{|c|c|c|c|c|}
\hline Personal experience $^{\dagger}$ & $\begin{array}{c}\text { Lagos } \\
(n=43)\end{array}$ & $\begin{array}{l}\text { Others } \\
(n=10)\end{array}$ & $\begin{array}{c}\text { Total } \\
(n=53)\end{array}$ & $P$ value \\
\hline \multicolumn{5}{|c|}{ Participation in anti-epidemic activities } \\
\hline No & $29(67.4)$ & $7(70.0)$ & $36(67.9)$ & 0.635 \\
\hline Yes & $14(32.6)$ & $3(30.0)$ & $17(32.1)$ & \\
\hline \multicolumn{5}{|c|}{ Current Status of orthodontic practice } \\
\hline Not resumed yet & $2(4.7)$ & $0(0)$ & $2(3.8)$ & 0.481 \\
\hline Resumed, 2 to 4 weeks & $0(0)$ & $1(10.0)$ & $1(1.9)$ & \\
\hline Resumed, more than 4 weeks & $40(93.0)$ & $9(90.0)$ & $49(92.5)$ & \\
\hline
\end{tabular}




\begin{tabular}{|l|c|c|c|c|}
\hline No suspension & $1(2.3)$ & $0(0.0)$ & $1(1.9)$ & \\
\hline Completion of COVID-19 related training program \\
\hline No & $2(4.7)$ & $0(0)$ & $2(3.8)$ & 0.998 \\
\hline Yes & $41(95.3)$ & $10(100.0)$ & $51(96.2)$ & \\
\hline Experience of treating or caring for COVID-19 patients & \\
\hline No & $37(86.0)$ & $10(100.0)$ & $47(88.7)$ & 0.954 \\
\hline Yes & $6(14.0)$ & $0(0)$ & $6(11.3)$ & \\
\hline
\end{tabular}

\section{Knowledge}

As described in Table 4, the mean self-perceived level of knowledge of COVID-19 was 4.44 (0.55), while the mean total knowledge score was $4.15(0.60)$.

Most respondents expressed agreement or complete agreement that they understood COVID-19- related knowledge, the risk of COVID-19 to patients and health care workers as well as how to protect themselves and patients during the epidemic. As shown in Figure 2, the Internet (98.1\%) was the respondents' primary source of knowledge, followed by television $(96.2 \%)$, medical journals $(92.5 \%)$, training programs $(83.0 \%)$, newspapers $(49.1 \%)$ and other sources $(5.7 \%)$.

Table 4 Respondents' COVID-19 related knowledge by profession

\begin{tabular}{|c|c|c|c|c|}
\hline Questions about knowledge & $\begin{array}{l}\text { Orthodontist } \\
\qquad N=29\end{array}$ & $\begin{array}{c}\text { Senior } \\
\text { Residents } \\
\mathrm{N}=16 \\
\end{array}$ & $\begin{array}{c}\text { Junior } \\
\text { Residents } \\
\mathbf{N}=\mathbf{8} \\
\end{array}$ & $\begin{array}{c}P \\
\text { value }\end{array}$ \\
\hline Self-perceived level of knowledge & $4.41(0.62)$ & $4.46(0.44)$ & $4.50(0.54)$ & 0.916 \\
\hline You understand the relevant knowledge of COVID-19• & $4(4-5)$ & $4.5(4-5)$ & $4.5(4-5)$ & 0.845 \\
\hline $\begin{array}{l}\text { You are confident that you understand the risks of } \\
\text { COVID- } 19 \text { epidemic for patients and HCWs }\end{array}$ & $5(4-5)$ & $4.5(4-5)$ & $4.5(4-5)$ & 0.527 \\
\hline $\begin{array}{l}\text { You are confident that you understand how to protect } \\
\text { yourself and your patients during COVID-19 epidemic }\end{array}$ & $5(4-5)$ & $4(4-5)$ & $4.5(4-5)$ & 0.231 \\
\hline Total knowledge score ${ }^{\ddagger}$ & $4.10(0.67)$ & $4.13(0.50)$ & $4.38(0.52)$ & 0.525 \\
\hline What is the correct $\mathrm{PPE}^{\dagger}$ & $18(62.1)$ & $13(81.3)$ & $8(100)$ & 0.069 \\
\hline $\begin{array}{l}\text { Hand hygiene includes either washing hands with soap } \\
\text { and water, or the use of an alcohol-based hand rub }{ }^{\dagger}\end{array}$ & $29(100)$ & $16(100)$ & $8(100)$ & - \\
\hline $\begin{array}{l}\text { It is adequate to use an alcohol-based hand rub if the } \\
\text { hands are visibly soiled }{ }^{\dagger}\end{array}$ & $29(100)$ & $16(100)$ & $8(100)$ & - \\
\hline Use of correct PPE eliminates the need for hand hygiene ${ }^{\dagger}$ & $29(100)$ & $16(100)$ & $8(100)$ & - \\
\hline $\begin{array}{l}\text { When should you wear goggles and a face shield at the } \\
\text { same time during treatment }{ }^{\dagger}\end{array}$ & $8(27.6)$ & 3 (18.6) & $1(12.5)$ & 0.603 \\
\hline $\begin{array}{l}\text { When could you only wear a surgical mask during } \\
\text { treatment }{ }^{\dagger}\end{array}$ & $6(20.7)$ & $2(12.5)$ & $2(25.0)$ & 0.711 \\
\hline
\end{tabular}

$\because$ Displayed as median (25th percentile - 75 percentile); ${ }^{\dagger}$ : Displayed as number and percentage of correct responses. Likert scale, ranging from 1 (completely disagree) to 5 (completely agree); ₹ Displayed as mean (SD)

Table 5 shows the results of regression analyses for self-perceived level of knowledge about COVID-19. According to multivariable analysis, respondents who worked in Government setting had significantly more confidence in their knowledge level than those who worked in other settings. ( $\mathrm{B}=-0.227, P=0.042)$. In addition, a significantly higher selfperceived level of knowledge was also found in those who had the experience of treating or caring for COVID-19 patients $(P=0.029)$. However, a higher total knowledge score (Table 6) was significantly associated with participation in anti- 
epidemic activities $(\mathrm{B}=-0.504, P=0.035)$ and provision of online consultations during the pandemic $(\mathrm{B}=0.300, P=$ $0.029)$.

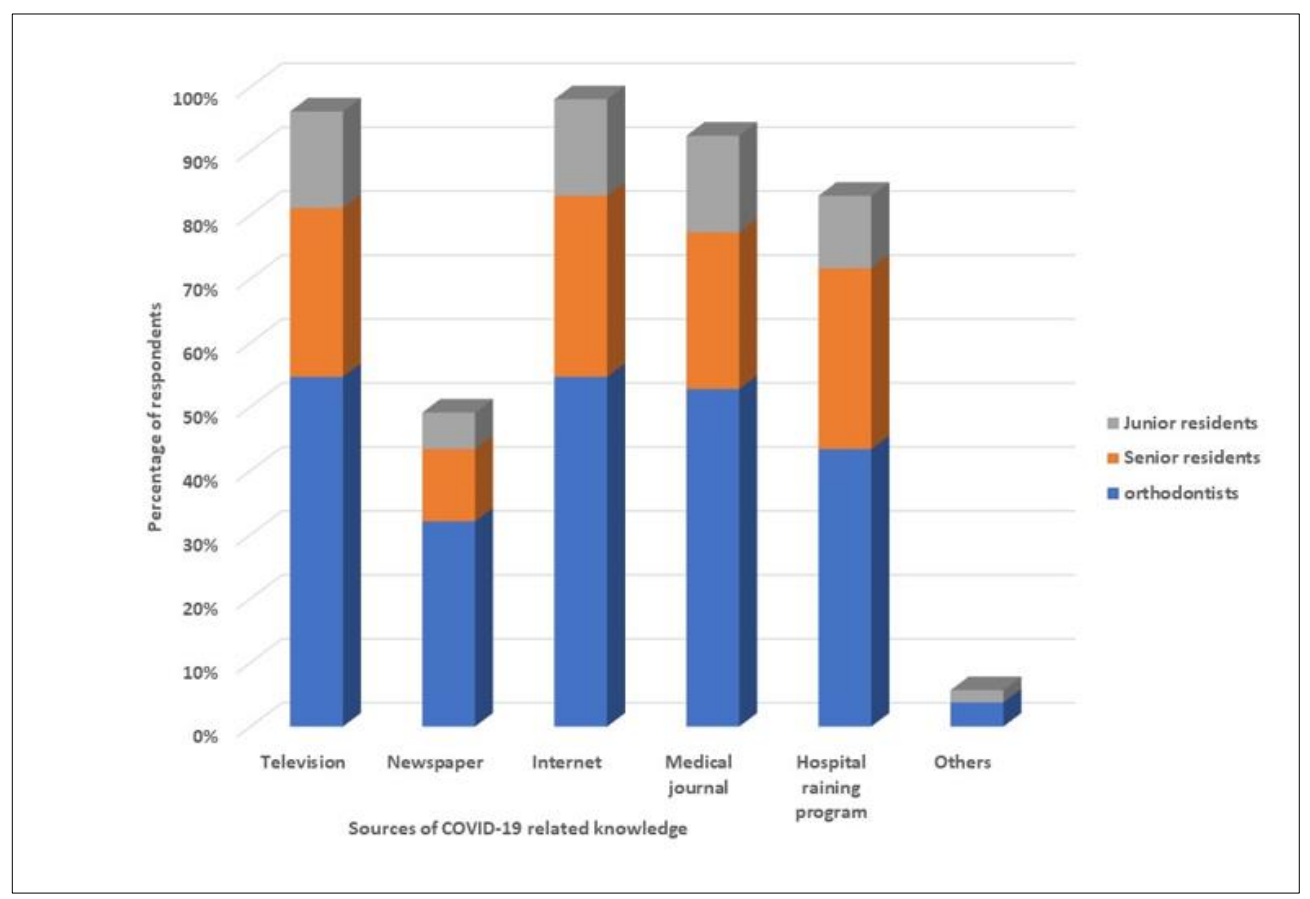

Figure 2 The sources of COVID-19-related knowledge among respondents (question \#15)

Table 5 Results of multivariable generalized linear regression analyses for self-perceived level of knowledge

\begin{tabular}{|c|c|c|c|}
\hline Model & $\mathbf{B}$ & CI & $\mathbf{P}$ \\
\hline \multicolumn{4}{|l|}{ Demographics } \\
\hline Age & -0.227 & $(-0.556,0.101)$ & 0.169 \\
\hline Gender & 0.101 & $(-0.314,0.517)$ & 0.625 \\
\hline Marital status & 0.007 & $(-0.255,0.269)$ & 0.956 \\
\hline Professional status & 0.206 & $(-0.158,0.570)$ & 0.260 \\
\hline Years of orthodontics practice & 0.052 & $(-0.162,0.266)$ & 0.623 \\
\hline \multicolumn{4}{|l|}{ Workplace information } \\
\hline Location of practice & -0.023 & $(-0.062,0.017)$ & 0.256 \\
\hline Work setting & -0.227 & $(-0.444,-0.009)$ & $0.042^{*}$ \\
\hline Provision of online consultation during the pandemic & 0.215 & $(-0.039,0.469)$ & 0.095 \\
\hline Status of orthodontic practice & -0.143 & $(-0.492,0.207)$ & 0.414 \\
\hline \multicolumn{4}{|l|}{ Personal experience } \\
\hline Participation in antiepidemic activities & -0.097 & $(-0.542,0.348)$ & 0.662 \\
\hline Status of orthodontic services & -0.020 & $(-0.335,0.295)$ & 0.897 \\
\hline Covid-19 related training & -0.166 & $(-1.148,0.815)$ & 0.733 \\
\hline Experience of treating COVID-19 suspected/confirmed patients & -0.667 & $(-1.263,-0.070)$ & $0.029^{*}$ \\
\hline
\end{tabular}


Table 6 Results of multivariable generalized linear regression analyses for total knowledge score

\begin{tabular}{|l|r|r|c|}
\hline Model & B & CI & P \\
\hline Demographics & -0.096 & $(-0.441,0.248)$ & 0.576 \\
\hline Age & 0.290 & $(-0.146,0.725)$ & 0.186 \\
\hline Gender & 0.196 & $(-0.079,0.471)$ & 0.158 \\
\hline Marital status & -0.164 & $(-0.546,0.218)$ & 0.390 \\
\hline Professional status & 0.163 & $(-0.062,0.387)$ & 0.151 \\
\hline Years of orthodontics practice & 0.034 & $(-0.008,0.075)$ & 0.109 \\
\hline Workplace information & -0.122 & $(-0.351,0.106)$ & 0.284 \\
\hline Location of practice & 0.300 & $(0.033,0.566)$ & $0.029^{*}$ \\
\hline Work setting & -0.186 & $(-0.552,0.180)$ & 0.311 \\
\hline Provision of online consultation during the pandemic & & \\
\hline Status of orthodontic practice & -0.504 & $(-0.971,-0.038)$ & $0.035^{*}$ \\
\hline Personal experience & -0.240 & $(-0.570,0.091)$ & 0.150 \\
\hline Participation in anti-epidemic activities & -0.020 & $(-1.050,1.009)$ & 0.969 \\
\hline Status of orthodontic services & -0.076 & $(-0.549,0.702)$ & 0.806 \\
\hline Covid-19 related training
\end{tabular}

$\mathrm{R} 2=0.423, \mathrm{~F}(14,3 ; 8)=1.990, \mathrm{P}=0.046 \mathrm{CI}=$ Confidence interval

\section{Attitude}

Most respondents agreed about the effectiveness of PPE. Table 7 shows the differences in attitude among professional status. Junior orthodontic residents felt less inconvenience using PPE when treating/caring for patients $(P=0.001)$ compared to other cadre of respondents. About 20.8\% $(n=11)$ of the participants stated their willingness to treat or care for patients with confirmed or suspected COVID-19. As depicted in Figure 3, among respondents who were unwilling to treat/care for COVID-19 patients, the most common reasons were concerns about the possible infection of themselves.

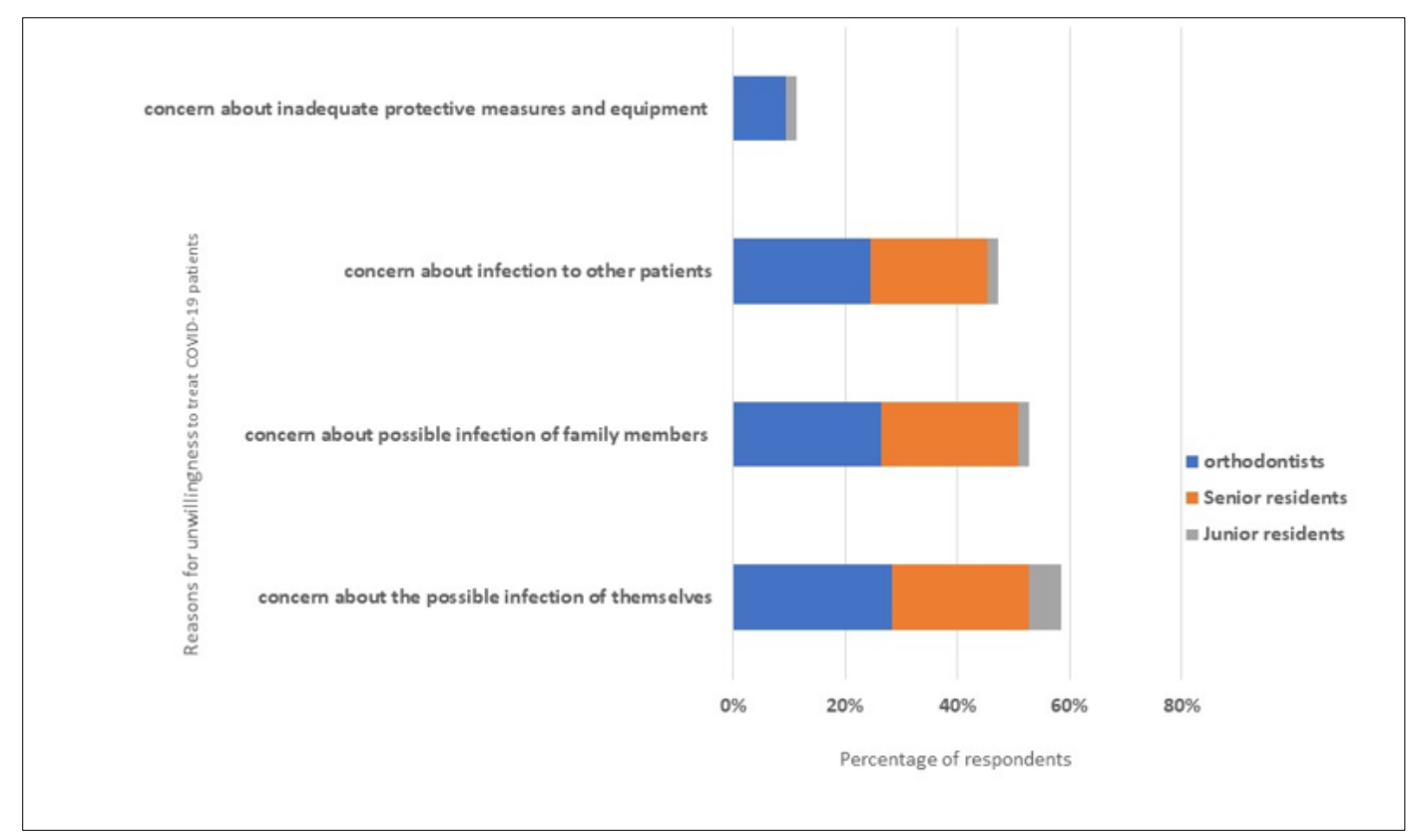

Figure 3 The reasons for being unwilling to treat or care for patients confirmed or suspected with COVID-19 (question \#29) 
Table 7 Respondents' attitude towards COVID-19 by profession

\begin{tabular}{|c|c|c|c|c|}
\hline Questions about attitude & $\begin{array}{l}\text { Orthodontist } \\
\quad \text { s }(n=29)\end{array}$ & $\begin{array}{l}\text { Senior } \\
\text { residents } \\
(n=16)\end{array}$ & $\begin{array}{l}\text { Junior } \\
\text { residents } \\
\quad(n=8)\end{array}$ & $P$ value \\
\hline $\begin{array}{l}\text { Use of PPE will keep orthodontic staffs from getting } \\
\text { COVID-19• }\end{array}$ & $4(3.5-5)$ & $4(4-5)$ & $4.5(4-5)$ & 0.685 \\
\hline $\begin{array}{l}\text { Use of PPE will keep orthodontic patients from } \\
\text { getting COVID-19. }\end{array}$ & $4(3-4)$ & $4(3-5)$ & $4.5(4-5)$ & 0.400 \\
\hline $\begin{array}{l}\text { A donning and doffing supervisor is necessary to } \\
\text { ensure PPE compliance }\end{array}$ & $4(2.5-4)$ & $4(4-5)$ & $5(4-5)$ & 0.135 \\
\hline $\begin{array}{l}\text { It is inconvenient to use recommended PPE when } \\
\text { treating / caring for patients }\end{array}$ & $3(2-5)$ & $4(4-4)$ & $3.5(3-4)$ & $0.001^{*}$ \\
\hline $\begin{array}{l}\text { Are you willing to treat / care for patients confirmed } \\
\text { or suspected with COVID-19 if you have the } \\
\text { opportunity }{ }^{+}\end{array}$ & $6(20.7)$ & $2(12.5)$ & $3(37.5)$ & 0.363 \\
\hline
\end{tabular}

\section{Behaviours}

This portion of the questionnaire asked the respondents about their behaviours after the resumption of orthodontic services (Table 8). Most respondents expressed agreement or complete agreement that their hospitals/clinics had adequate PPE for them to use, but they can improve their compliance with the recommended PPE requirements for orthodontic treatment. However, Senior orthodontic registrars were less likely to use pre-procedural mouth rinse with $1 \%$ Hydrogen Peroxide or $0.2 \%$ povidone Iodine $(P=0.034)$ compared to orthodontic specialists. There was a general low compliance with the use of high-volume evacuators during aerosol generating procedures.

Table 8 Respondents' COVID-19 related behaviors by profession

\begin{tabular}{|l|c|c|c|c|}
\hline \multicolumn{1}{|c|}{ Questions about behaviors } & $\begin{array}{c}\text { Orthodontists } \\
\text { (n=29) }\end{array}$ & $\begin{array}{c}\text { Senior } \\
\text { residents } \\
\text { (n=16) }\end{array}$ & $\begin{array}{c}\text { Junior } \\
\text { residents } \\
\text { (n=8) }\end{array}$ & P value \\
\hline $\begin{array}{l}\text { Asking every Patient's Travel History before } \\
\text { Performing orthodontic Treatment }\end{array}$ & $19(65.5)$ & $11(68.8)$ & $4(50.0)$ & 0.648 \\
\hline $\begin{array}{l}\text { Asking every Patient about History of cough and } \\
\text { difficulty in breathing before Performing Dental } \\
\text { Treatment }\end{array}$ & $27(93.1)$ & $13(81.3)$ & $7(87.5)$ & 0.483 \\
\hline $\begin{array}{l}\text { Taking every Patient's Body Temperature before } \\
\text { Performing Dental Treatment }\end{array}$ & $25(86.2)$ & $14(87.5)$ & $8(100)$ & 0.543 \\
\hline $\begin{array}{l}\text { Are You Deferring Dental Treatment of Patients } \\
\text { Showing Suspicious Symptoms }\end{array}$ & $27(93.1)$ & $16(100)$ & $8(100)$ & 0.423 \\
\hline $\begin{array}{l}\text { Have You Ever Worn a fit tested N95 or FFP2 } \\
\text { respirator (or higher) mask while treating a } \\
\text { Patient in your Orthodontic Practice }\end{array}$ & $16(55.2)$ & $11(68.8)$ & $5(62.5)$ & 0.666 \\
\hline $\begin{array}{l}\text { All recommended PPE is readily available in your } \\
\text { hospital or clinic }\end{array}$ & $4(2.5-4)$ & $3(2-4)$ & $4(3.25-4)$ & 0.387 \\
\hline $\begin{array}{l}\text { You will remove your PPE immediately when you } \\
\text { leave the treatment room }\end{array}$ & $4(4-5)$ & $4(4-5)$ & $5(4-5)$ & 0.877 \\
\hline
\end{tabular}




\begin{tabular}{|c|c|c|c|c|}
\hline $\begin{array}{l}\text { You believe that you can improve the compliance } \\
\text { to recommended PPE }\end{array}$ & $5(3-5)$ & $4.5(4-5)$ & $4(4-5)$ & 0.117 \\
\hline $\begin{array}{l}\text { Do You Ask Every Patient to Rinse His/Her Mouth } \\
\text { with } 1 \% \text { hydrogen peroxide or } 0.2 \% \text { povidone } \\
\text { iodine before Treatment }{ }^{\dagger}\end{array}$ & $22(75.9)^{b}$ & $6(37.5)^{a}$ & $4(50.0)^{\mathrm{a}, \mathrm{b}}$ & $0.034^{*}$ \\
\hline $\begin{array}{l}\text { Do You Use High-Volume Suction during aerosol } \\
\text { generating procedures in Your Practice for Every } \\
\text { Patient }^{+}\end{array}$ & $12(41.4)$ & $3(18.8)$ & $3(37.5)$ & 0.300 \\
\hline
\end{tabular}

\section{Discussion}

The coronavirus pandemic has significantly affected health care delivery especially in dental care due to the characteristics of dental practice settings and a high risk of cross infection between patients and dental health practitioners [1]. As a result of this, many national dental associations all over the world, including the Nigerian, American, and British Dental Associations recommended to close down dental clinics during this period or significantly scale down the level of dental care provided, to strictly emergency dental care, while all elective dental procedures were suspended to fight against the COVID-19 pandemic and ensure the safety of patients and medical staff [11-14]. Thus, there have been significant disruptions to dental care all over the world as the profession grapples with establishing standard protocols for care during this period.

Likewise, orthodontic care has also been affected by the pandemic. Although, the Standard Operating Procedures for Dental Practice in Nigeria during this study duration was for Emergency Dental Services, the Standard Operational Procedures for Dental Practice in Nigeria was reviewed in October 2020 from Emergency Dental Services to Essential Dental Services due to the rapid reduction in the transmission of COVID-19 pandemic in the Country [15].

In the present study, 51(96.2\%) of respondents were providing orthodontic services during the period of this data collection (Table 2). These figures differ from those of a previous study conducted among Nigerian orthodontists and orthodontic residents between April and May 2020, which found suspension of orthodontic practice, lower patient turnout, and provision of only emergency services as effects of the pandemic on orthodontic practice [7].

This study found that $83 \%$ of respondents reported that the training was their primary source of COVID-19-related information (Figure 2). Therefore, it is imperative that the various training institutions provide adequate infection prevention and control (IPC) training for their specialists and residents, particularly about COVID-19. The importance of continuous education courses for orthodontists that are focused on infection control for COVID-19 is further reinforced by the fact that standard protective measures in daily clinical work are not effective enough for the prevention of the spread of COVID-19 in the dental clinic, particularly when patients are in the incubation period, are unaware they are infected, or intentionally conceal their infection [1]. Thus, it is also very likely that in the near future, most dental regulatory bodies may require this training or continuous education in this area, as being mandatory, to ensure that all dentists and dental specialists, particularly orthodontists, receive the required training in this regard, based on the huge risks involved in providing dental or orthodontic care at this period without having adequate knowledge of the proper precautions to take.

In the present study, most respondents (96.2\%) had finished COVID-19-related training programs (Table 3). This contrasts with a previous study conducted between April and June 2020, which found only $34.6 \%$ of dentists in residency training programs in Nigeria had completed a formal COVID-19 related infection control training [16]. The role of proper infection control and the use of universal precautions in the prevention of COVID-19 particularly in the dental setting cannot be overstated. Effective infection prevention and control is central to providing high-quality health care for patients and a safe working environment for those that work in healthcare settings. If adequate precautions are not taken, the dental office can potentially expose patients and operators to numerous infections.

Responses to our questions regarding knowledge have shown an agreement between the self-perceived and actual level of knowledge. Most respondents stated that they understood COVID-19-related knowledge, risks, and protective measures very well, their total knowledge score was also generally optimal (Table 4). Multivariable analyses revealed that experience of treating COVID-19 suspected or confirmed patients and types of orthodontic clinic settings were significantly associated with a higher level of self-perceived knowledge (Table 5). 
According to multivariable analyses, participation in anti-epidemic activities was significantly associated with a higher total knowledge score (Table 6). This is consistent with previous studies, which suggested the importance of community mitigation in the control of disease outbreaks [17]. This finding highlights the importance for dental hospitals, clinics, and relevant professional societies to organize adequate anti-epidemic activities like supporting designated hospitals, community organising for health care workers.

According to multivariable analyses, participation in online consultations was significantly associated with a higher total knowledge score (Table 6). Previous studies conducted in a Chinese population found that 87.4\% of orthodontic practices and $68.8 \%$ of dental practices had been offering online dental consultations during suspension of clinical activities [18]. Furthermore, recent studies have reported the effectiveness of teledentistry or virtual-based consultation in maintaining communication with patients during pandemic periods $[15,19,20]$. Online consultations provides an alternative means of addressing minor orthodontic emergencies, while also making it possible to remotely monitor the progress made by patients. It also creates an opportunity to advise them on patient-dependent treatment procedures, such as changing elastics.

About the respondents' attitude, only 11(20.8\%) of them were willing to treat/care for patients with confirmed or suspected COVID-19 (Table 7). Those who were reluctant (Figure 3) expressed their concern over fear of getting infected (73.8\%) and possible infection of their family members (66.7\%). Researchers found that fear of transmitting the virus to family and getting infected themselves was the top concern of orthodontic practitioners and staff [21].

In the present study, most respondents agreed that they could improve their adherence to PPE recommendations although there was poor compliance with the use of high-volume evacuators during aerosol generating procedures (Table 8). A previous study indicated that dental practitioners were generally ill prepared for COVID-19, as they did not routinely wear recommended respirators during treatment [22]. The use of PPE is crucial for protection, and practitioners need to understand which level of protective measures should be used [5]. Hand hygiene is also considered a critical measure for infection control, with poor adherence believed to be a major contributor to disease transmission [23]. Previous studies found that the implementation of recommended infection control measures varied among dentists, and those who were aware of the importance of infection control had better compliance with guidelines [24]. This suggests that the use of effective strategies and different modes of training is necessary to enhance dental professionals' awareness of infection control. Recommendations were made for the use of a checklist in handy places for repeatable procedures to improves compliance with infection control precautions, including what PPE should be used in certain circumstances, the correct donning and doffing procedures of PPE, and the recommended hand hygiene measures [25].

This study has several limitations, one of which is that environmental differences may affect the perceptions of impact, thus it may not be able to directly extrapolate some of the results of this study to orthodontists practicing in other countries. Although a questionnaire-based survey is a useful tool to efficiently acquire information regarding opinions and experiences covering wide demographics of participants [26], careful interpretation of the results is required. Furthermore, because of the unusual nature of the pandemic and the unknown length of time of the lockdown in different parts of the world, the impact may vary from one region to the other, based on the duration of the lockdown experienced. However, the results from this study provide a baseline for future studies. In addition, a more thorough investigation into the impact of COVID-19 on orthodontists' provision of healthcare services was out of the scope of this study and therefore not included. This could be explored in future research.

\section{Conclusion}

Results of the present study suggest that, during the mitigation stage of the COVID-19 epidemic when orthodontic services were gradually resuming, orthodontic professionals in Nigeria were generally confident that they understand COVID-19-related risks and knowledge, but only about $20.8 \%$ of them were willing to treat or care for COVID-19 patients. COVID-19-related training programs are essential for the improvement of knowledge, confidence, and preparedness of orthodontic professionals. Sufficient and proper protection should also be provided to ensure safety and reduce the psychological burden on them.

\section{Compliance with ethical standards}

\section{Acknowledgments}

The authors appreciate and thank all contributors. 


\section{Disclosure of conflict of interest}

All authors hereby declare that there is no relationship with any party that may present a potential conflict of interest.

\section{Statement of ethical approval}

The present research work does not contain any studies performed on animals/humans subjects by any of the authors.

\section{Statement of informed consent}

Informed consent was obtained from all individual participants included in the study.

\section{References}

[1] Meng L, Hua F, Bian Z. Coronavirus disease 2019 (COVID-19): emerging and future challenges for dental and oral medicine. J Dent Res. 2020 May;99(5):481-7.

[2] Pan A, Liu L, Wang C, Guo H, Hao X, Wang Q, et al. Association of public health interventions with the epidemiology of the COVID-19 outbreak in Wuhan, China. JAMA. 2020 May;323(19):1915-23.

[3] Nigeria Centre for Disease Control (NCDC). Infection prevention and control guideline for Covid-19. 2020.

[4] Nigeria Centre for Disease Control (NCDC). Infection prevention and control guideline for Covid-19. 2020.

[5] Peng X, Xu X, Li Y, Cheng L, Zhou X, Ren B. Transmission routes of 2019-nCoV and controls in dental practice. Int J Oral Sci. 2020 Mar;12(1):9.

[6] Herron JB, Hay-David AG, Gilliam AD, Brennan PA. Personal protective equipment and Covid 19-a risk to healthcare staff? Br J Oral Maxillofac Surg. 2020 Jun;58(5):500-2.

[7] Isiekwe IG, Adeyemi TE, Aikins EA, Umeh OD. Perceived impact of the COVID-19 pandemic on orthodontic practice by orthodontists and orthodontic residents in Nigeria, J World Fed Orthod. 2020 Sep;9(3):123-8.

[8] Lawal OA. Evaluation of orthodontic residency training programme in Nigeria: perils and pitfalls from residents' perspective. West Afr J Orthod. 2016;5:5-9.

[9] Ilesanmi O, Afolabi A. Perception and practices during the COVID-19 pandemic in an urban community in Nigeria: a cross-sectional study. PeerJ. 2020; 8: e10038.

[10] Hua F, Qin D, Yan J, Zhao T, He H. COVID-19 Related Experience, Knowledge, Attitude, and Behaviors Among 2,669 Orthodontists, Orthodontic Residents, and Nurses in China: A Cross-Sectional Survey. Front Med. 2020;7:481.

[11] Nigerian Dental Association. NDA recommendations on Covid-19 protocol for dental clinics. The American Dental Association. 2020 Mar 27. Coronavirus frequently asked questions. 2020.

[12] Centers for Disease Control and Prevention. 2020 Mar 27. CDC recommendation: postpone non-urgent dental procedures, surgeries, and visits. 2020.

[13] Cotrin PP, Peloso RM, Oliveira RC, Oliveira RCG, Pini NIP, Valarelli FP, et al. Impact of coronavirus pandemic in appointments and anxiety/concerns of patients regarding orthodontic treatment. Orthod Craniofac Res. 2020 May;23(4):455-61.

[14] Saltaji H, Sharaf KA. COVID-19 and orthodontics-a call for action. Am J Orthod Dentofacial Orthop. 2020 Jul;158(1):12-3.

[15] COVID-19: Guidelines/Standard Operational Procedures for dental practice in Nigeria. 2021.

[16] Isiekwe IG, Umeizudike KA, Daramola O0, Akeredolu MO, Leo-Olagbaye AA. The COVID-19 pandemic and dental residency training in Nigeria. Eur J Dent Educ. 2020 Dec 28. doi: 10.1111/eje.12654.

[17] Ogboghodo EO, Osaigbovo II, Obaseki DE, Nneka Okwara OH, Omo-Ikirodah OT, Adio F, et al. Community mitigation strategies for coronavirus disease 2019: An assessment of knowledge and adherence amongst residents of Benin City, Edo State, Nigeria. Niger Postgrad Med J. 2021 Jan-Mar;28(1):14-21.

[18] Yang Y, Zhou Y, Liu X, Tan J. Health services provision of 48 public tertiary dental hospitals during the COVID-19 epidemic in China. Clin Oral Investig. 2020 May;24(5):1861-4.

[19] Suri S, Vandersluis YR, Kochhar AS, Bhasin R, Abdallah MN. Clinical orthodontic management during the COVID19 pandemic. Angle Orthod. 2020 Jul; 90(4):473-84. 
[20] Caprioglio A, Pizzetti GB, Zecca PA, Fastuca R, Maino G, Nanda R. Management of orthodontic emergencies during 2019-NCOV. Prog Orthod. 2020;21:10.

[21] Ahmed MA, Jouhar R, Ahmed N, Adnan S, Aftab M, Zafar MS, et al. . Fear and practice modifications among dentists to combat novel Coronavirus Disease (COVID-19) outbreak. Int J Environ Res Public Health. 2020 Apr;17(8):2821.

[22] Ren YF, Rasubala L, Malmstrom H, Eliav E. Dental care and oral health under the clouds of COVID-19. JDR Clin Trans Res. 2020 Jul;5(3):202-10.

[23] Kampf G, Kramer A. Epidemiologic background of hand hygiene and evaluation of the most important agents for scrubs and rubs. Clin Microbiol Rev. 2004 Oct;17(4):863-93.

[24] Cleveland JL, Foster M, Barker L, Brown GG, Lenfestey N, Lux L, et al. Advancing infection control in dental care settings: factors associated with dentists' implementation of guidelines from the Centers for Disease Control and Prevention. J Am Dent Assoc. 2012 0ct;143(10):1127-38.

[25] Kohn WG, Harte JA, Malvitz DM, Collins AS, Cleveland JL, Eklund KJ. Centers for Disease Control and Prevention. Guidelines for infection control in dental health care settings--2003. J Am Dent Assoc. 2004;135:33-47.

[26] Kelley K, Clark B, Brown V, Sitzia J. Good practice in the conduct and reporting of survey research. Int J Qual Health Care. 2003 Jun;15(3):261-6. 